\title{
Areal Linguistics and Mainland Southeast Asia
}

\author{
N.J. Enfield
}

Language and Cognition Group, Max Planck Institute for Psycholinguistics, PB 310, 6500 AH, Nijmegen, The Netherlands; email: Nick.Enfield@mpi.nl

Annu. Rev. Anthropol.

2005. 34:181-206

First published online as a

Review in Advance on

June 14, 2005

The Annual Review of

Anthropology is online at

anthro.annualreviews.org

doi: $10.1146 /$

annurev.anthro.34.081804.120406

Copyright (C) 2005 by

Annual Reviews. All rights

reserved

0084-6570/05/1021-

$0181 \$ 20.00$

\section{Key Words}

diffusion of innovation, linguistic epidemiology, cultural evolution, human diversity, methodological individualism, historical linguistics

\section{Abstract}

Mainland Southeast Asia provides a dramatic demonstration of the areal phenomenon in linguistics: When languages are spoken historically in the same location they often show significant parallels in the organization of a wide range of structural domains, whether the languages descend from the same historical source. The effects of areal diffusion raise fundamental questions for the traditional essentialist vision of languages as entities with offspring that diverge, with shared innovations marking divergent branches and internal processes of evolution accounting for diversity among modern languages. Recent theoretical and empirical research on linguistic diversity, language change, and social diffusion of innovation argues for a unit-based approach to language change and relatedness, where the units of analysis are individual speakers and individual linguistic items. This review begins with discussion of the language situation in Mainland Southeast Asia, where the language "genealogies" have been dramatically permeated by socio-historical contact, then explores theoretical and methodological implications for research on language both generally and in its areal context. 


\section{Contents}

INTRODUCTION.............. 182

MAINLAND SOUTHEAST ASIA. . 182

Sociolinguistic History of MSEA.. 184

Typological Linguistics

of Modern MSEA .......... 186

AREAL LINGUISTICS .......... 190

Linguistic Areas ............. 190

Inheritance versus Diffusion ...... 192

The Lesson of Areal Linguistics:

Language as a Unit-Based

Population Phenomenon ...... 194

CONCLUSION ................ 197

\section{INTRODUCTION}

Areal linguistics: seeks to document and understand the phenomenon of parallel structural organization in languages (typically, languages of different families), which are spoken in the same or adjoining geographical areas.
Mainland Southeast Asia is one among many areas of the earth's surface in which languages of different origins have come to share structural properties at multiple levels owing to historical social contact between speech communities. Areal linguistics is concerned with this phenomenon-that languages can become structured in the same ways by virtue of being spoken in the same geographical area. This field of research can lead us to question the abstracted and essentialized nature of the object of inquiry traditionally presupposed in linguistics, a system transcending the abilities and practices of individual speakers and with unit status at the community level, and through historical time. The discipline of historical linguistics has portrayed relatedness between languages as one of speciation, commonness due to shared ancestry, and difference due to modification along different lines of descent. But areal linguistics reveals that the traditionally assumed unified systematicity of a language is highly permeable. We are forced to look and see that "languages" are populations of associated units, cognitively embodied, socially deployed, and sociometrically aggregated. Included among such units or items are phonological elements, grammatical elements, words, con- structions, and idioms. The apparent system coherence of a community's linguistic codeour intuitive sense that there is "a language"emerges by aggregation under the centripetal force of social group interaction in the vast economies of linguistic and cultural currency maintained by populations such as those strewn across the Mainland Southeast Asia area.

\section{MAINLAND SOUTHEAST ASIA}

Mainland Southeast Asia (MSEA) is defined in this review as the region encompassing Vietnam, Laos, Cambodia, and Thailand, with some extension west into Burma, south into Peninsular Malaysia, and north into southern China. See Figure 1.

The region of interest might otherwise be characterized as the place in which languages of the Tai-Kadai, Mon-Khmer, Sino-Tibetan, Hmong-Mien, and Austronesian language families are in contact.

MSEA has seen some 2000 years of social contact among hundreds of speech communities speaking languages from at least five major language families. The result has been extensive diffusion of linguistic structure leading to massive structural convergence among the languages. As a sample illustration, compare the vowel systems of Cham, Khmer, and Lao, three genealogically unrelated languages spoken in close proximity southeast of the MSEA peninsula (Table 1).

The sets of phonological contrasts in vowel quality are closely comparable in the three languages, with 9-10 distinct vowels (including high central unrounded vowels) and length contrasts for most. That this close similarity is contact induced is clear when we consider Cham in the context of other Austronesian languages, whose vowel systems are normally much simpler than this, with $\sim 4$ vowels (Himmelmann \& Adelaar 2005). Cham has undergone radical change under pressure from Mon-Khmer (Thurgood 1999). Similarly, Tai languages further north of Lao have simpler vowel systems. 


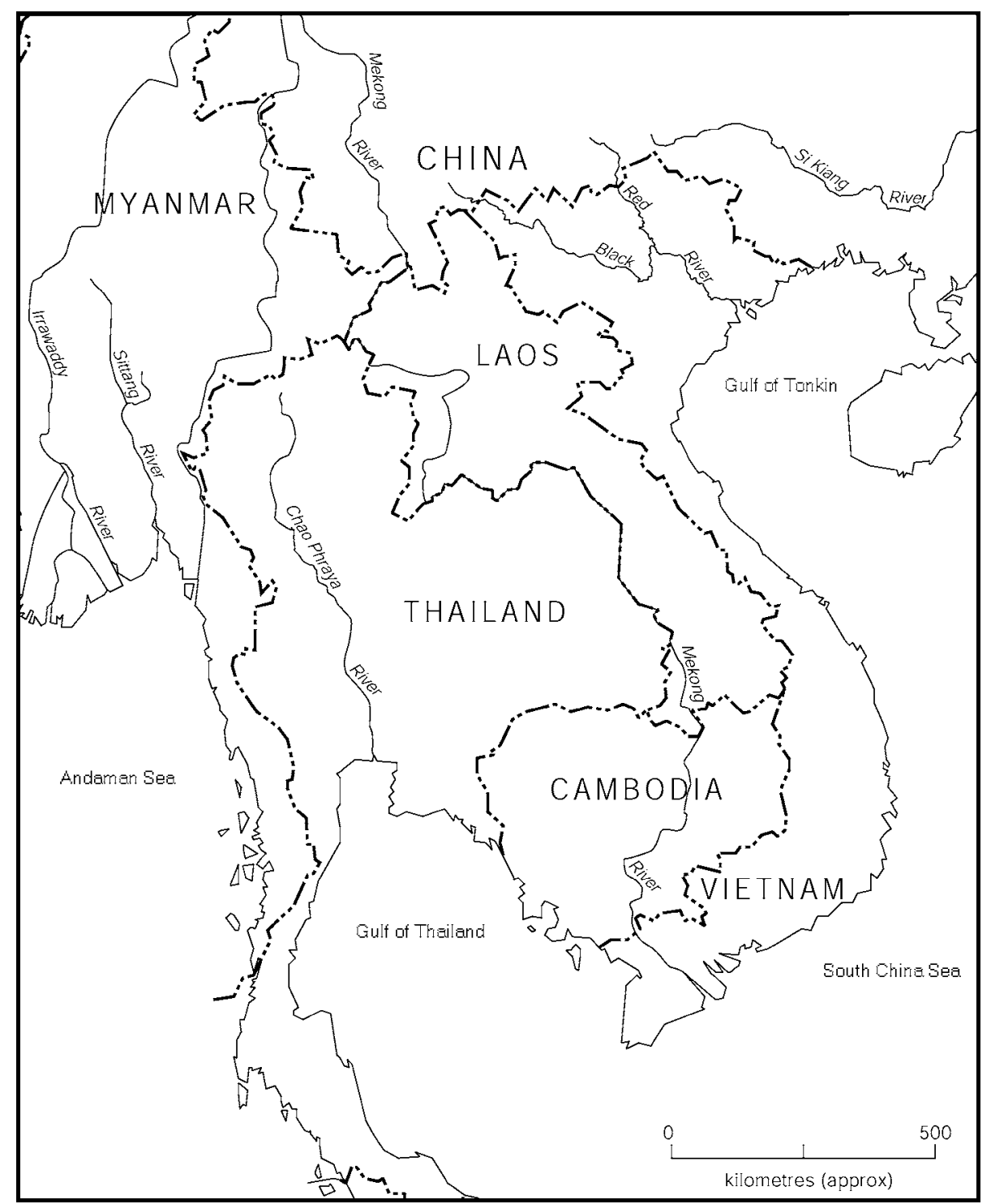

Figure 1

Mainland Southeast Asia, political, with rivers.

Five main language families overlap and intermingle in MSEA. These are MonKhmer, Tai-Kadai, Hmong-Mien, SinoTibetan, and Austronesian. Mon-Khmer is a major language family represented throughout MSEA, running down to peninsular Malaysia and west across to northeast India and the Andaman Sea (Diffloth 1974, Diffloth
\& Zide 1992). Mon-Khmer languages-the best known being Vietnamese and Khmer, with national language status-are especially numerous and diverse in inland areas of central MSEA; languages of several subbranches are spoken in the narrow highlands of Central and Southern Laos and Vietnam and Northeast Cambodia. 
Table 1 Simple phonological vowel distinctions of three neighboring MSEA

languages, not genealogically related

\begin{tabular}{|c|c|c|c|c|c|c|c|c|}
\hline i i: & $\dot{i}$ í: & u u: & $\mathrm{i}$ i: & $\dot{\mathrm{i}} \mathrm{i}:$ & $\mathrm{u}$ u: & i i: & $\dot{i}$ i: & $\mathrm{u}$ u: \\
\hline e e: & ə ə: & o $\quad$ o: & e & ə $ә:$ & O O: & e e: & ə ว: & o o: \\
\hline$\varepsilon:$ & a a: & a $\quad$ a: 0 o: & $\varepsilon \varepsilon:$ & a a: & 0 o: & $\varepsilon \varepsilon:$ & a a: & 0 o: \\
\hline \multicolumn{3}{|c|}{$\begin{array}{l}\text { Khmer (Mon-Khmer; } \\
\text { Cambodia, Thailand) }\end{array}$} & \multicolumn{3}{|c|}{$\begin{array}{l}\text { Cham (Austronesian; } \\
\text { Cambodia, Vietnam) }\end{array}$} & \multicolumn{3}{|c|}{$\begin{array}{c}\text { Lao (Tai; Laos, } \\
\text { Thailand, Cambodia) }\end{array}$} \\
\hline
\end{tabular}

MSEA: Mainland Southeast Asia; region that centers on Vietnam, Laos, Cambodia, and Thailand, with some scholars proposing further extension west into Burma, south into Peninsular Malaysia, and north into southern China. MSEA is the region in which languages of the Tai-Kadai, Mon-Khmer, Sino-Tibetan, Hmong-Mien, and Austronesian language families are in contact.
The Tai-Kadai language family consists of two major branches: Kadai, a complex of minority languages spoken in Guanxi, Guizhou, Yunnan, and Guangdong Provinces of Southwestern China, the area considered the homeland of the language family; and Tai, a homogeneous subbranch spreading broadly west across MSEA and into highland Burma and northeast India (Diller \& Edmondson 2005). In Nichols' (1992, pp. 16-21) terms, Tai languages constitute a spread zone (low structural diversity, shallow time depth, socially dominant), and Kadai a residual zone (high structural diversity, greater time depth, no clear center of innovation). Tai languages have a large number of speakers (e.g., Zhuang with some 10 million speakers in China, Lao with some 20 million in Laos and Thailand, and Siamese-i.e., Thai-with some 60 million in Thailand). The history and genealogical structure of Tai are well established (Gedney 1989, Li 1977, Luo 1997).

Hmong-Mien languages are spoken by vibrant (and, recently, expansive) minority communities traditionally located in China, and with intensive historical contact with Sinitic language and culture. Recent times have seen significant southward migrations into Thailand, Laos, and Vietnam (Culas \& Michaud 2004). The genealogical structure of the family is not yet well established (Ratliff 2004, Strecker 1987).

The Sino-Tibetan language family stretches far north through China and northwest across the Himalayas (Benedict 1972, Matisoff 1991b, Thurgood \& La Polla 2003). Branches of Sino-Tibetan with a presence in MSEA include Loloish languages spoken in the highlands of Burma, northern Laos, northern Thailand, and southwestern China (Bradley 2003), and Sinitic, the group of languages often referred to collectively as Chinese (Chappell 2001b, Norman 1988). Although they are commonly called dialects, Sinitic languages are distinct, non-mutually intelligible languages. A cultural ideology of Chinese unity has encouraged linguistic researchers not to see internal differences within Sinitic, following a long-assumed view, in the words of the authoritative Mandarin grammarian Chao Yuen Ren, that "there is practically one universal Chinese grammar" (Chao 1968, p. 13). Recent developments in Sinitic linguistics show this to be far from true. Many researchers are now investigating Sinitic languages in their areal context, i.e., not only as Sinitic varieties, but as languages with consequential historical contact with other languages of East and Southeast Asia (Ansaldo 1999; Ansaldo \& Matthews 2001; Bauer 1996; Chappell 2001a,b; Enfield 2003b; Simpson 2001; Sybesma 2004).

The Austronesian family is represented in MSEA only by languages of the Chamic group (Thurgood 1999). Languages of the Austronesian family dominate Insular Southeast Asia (Himmelmann \& Adelaar 2005).

\section{Sociolinguistic History of MSEA}

MSEA geography is dominated by major river systems running north to south (see Figure 1). In their Southern reaches, these rivers empty into wide plains now dominated by dense populations of paddy farmers speaking varieties of Vietnamese, Khmer, Siamese, and Lao. Highland areas north of these plains and running south along the 
Annamite Cordillera are home to ethnic minorities who practice mostly shifting agriculture (i.e., slash-and-burn). This pattern has resulted from major migrations over the past two millennia, mostly southward from China toward the lowlands. The most significant historical migrations have been the southwest fanning spread of Tai speakers from southwest China (Enfield 2003b, Wyatt 1984). Tai speakers came in search of flat land on which to work paddy fields using their distinctive ditch-and-dike system (Hartmann 1998). They encountered MonKhmer- and Sino-Tibetan-speaking communities who responded by either receding to higher land or becoming Tai, linguistically and culturally (Condominas 1990). Leach (1964 [1954]) describes this process in highland Burma involving Shan (Tai) and Jinghpaw/Kachin (Tibeto-Burman) speakers. The outcome of the Southwestern Tai migrations is a Tai spread zone covering large areas of MSEA, with residual zones in the uplands containing languages of other families such as Mon-Khmer. See Moseley \& Asher (1994, maps 48-51) for dramatic visual representation of this. Microcosms of this type of pattern can be observed throughout the area at a smaller scale.

Not all of today's MSEA Tai speakers are descendents of earlier Tai-speaking incomers. Tai speakers had political, cultural, and technological influence, such that "existing populations ... adopted, or were forced to adopt, the languages of their new overlords" (Stuart-Fox 1998, p. 29). Accordingly, a human genetic study (Samerchai 1998) found that Siamese-speaking people of the lowlands of Thailand share more genetic material with Khmer-speaking inhabitants of Cambodia than with Tai-speaking inhabitants of southern China. The process of language and culture shift toward dominant Tai societies is still in full swing, with widespread language loss in favor of major languages like Lao and Siamese. (The same is happening, mutatis mutandis, in Cambodia, Vietnam, China, and Burma.)
The newest arrivals in the MSEA area are Hmong-Mien speakers from southern China, having arrived in Laos, Thailand, and Vietnam within the past couple hundred years (Culas \& Michaud 2004).

One outcome of these historical trends in migration and interethnic relations is a sociocultural distinction between upland minority peoples and lowland majority peoples. The lowlanders' political and economic dominance has brought mass media, literacy, language standardization, etc., to their languages (e.g., Enfield 1999, Nguyen 1980). Such status can have structural effects; the decontextualized settings of literature and media create a need for more explicit morphosyntactic marking than is required in contextsituated conversation (Blake 2001; Diller 1988, 1993; Diller \& Khanittanan 2002). Also more closely associated with national language status in MSEA are multilevel socially deictic pronoun systems (Cooke 1968), which are less developed (but nevertheless present) in the minority languages. Speakers of majority languages tend to be monolingual, unlike minority people.

Cross-cutting the upland/lowland (subordinate/dominant, minority/majority) divide is a second major sociocultural distinction arising from historical developments at an international level. MSEA may be divided into an indosphere and a sinosphere, two distinct spheres of political, cultural, and religious influence from India and China, respectively (Matisoff 1991b, p. 485). Vietnamese, for instance, has changed radically from its MonKhmer cousins owing to Vietnam having been a province of China for nearly 1000 years, until 939 A.D. (Nguyen 1980). Much of the tangible culture of the Vietnamese-speaking world is Chinese in style. Even the language was long written using Chinese characters. By contrast, Khmer-, Lao-, and Siamese-speaking societies have long been under Indic influence in religion, art, and other cultural iconography (Chandler 1996, Evans 1999, Wyatt 1984), whereas languages of the Northern Tai and Kadai branches are well in the sinosphere.
Indosphere: a socio-political sphere of MSEA, subsuming those countries, cultures, and languages that have historically come under influence from the politics, culture, religion, and languages of India (notably, Laos, Thailand, Cambodia, Burma).

Sinosphere: a socio-political sphere of MSEA, subsuming those countries, cultures, and languages that have historically come under influence from the politics, culture, religion, and languages of China (notably Vietnam, Southwestern China, northern parts of Laos, as well as most urban centers in MSEA). 
To be expected, there is leakage across these axes of sociocultural difference. Sinitic languages have greatly influenced indospheric societies, as evidenced for example by Sinitic borrowings in Lao including numerals and terms for common things like paper, horse, and table. By comparison, crosscutting the Indic/Sinitic distinction is a substrate of upland indigenous cultural background, mostly Mon-Khmer or Austroasiatic (Steinberg 1987). Thus, for example, in ostensibly Indospheric Thailand, Laos, and Cambodia, religious practices include not only Indic (Buddhist) elements but elements of the animist practices, which are the primary religious practices of upland minority societies. Correspondingly, because of increased contact with dominant lowland cultures, upland societies are adopting aspects of mainstream lowland culture.

Historical patterns in MSEA show that migration, interethnic contact, and multilingualism have been the rule for hundreds of years. A broad distribution of dominant (especially Tai) languages along rivers and plains, with other languages on the slopes and peaks between, results in the lattice of languages underlying the great structural convergence we witness today.

\section{Typological Linguistics of Modern MSEA}

Despite a large volume of published work on the MSEA languages no comprehensive handbook or monograph coverage exists. Comrie (1990), Bradley (1994), and Goddard (2005) are useful sources with broader scope, covering East Asia as well. Description and analysis of MSEA languages may be found in a number of area-specific edited volumes and conference proceedings (e.g., Bauer 2002; Bradley 1989; Burusphat 2000; Edmondson \& Solnit 1988, 1997; Harris \& Chamberlain 1975; Nguyen 1974; Ratanakul et al. 1985). A number of authors have written overviews or partial descriptions of typological proper- ties of MSEA languages, areally defined (e.g., Bisang 1996; Budge 1980; Capell 1979; Clark 1985, 1989, 1996; Clark \& Prasithrathsint 1985; Enfield 2003b; Matisoff 1978, 1991a, 2001; Migliazza 1996). Grammatical descriptions include major languages of the area (e.g., Hospitalier 1937, Huffman 1970, Iwasaki \& Ingkaphirom 2005, Jacob 1968, Matthews \& Yip 1994, Noss 1964, Reinhorn 1980, Thompson 1987 [1965]), as well as minor languages (e.g., Alves 2000; N.J. Enfield, manuscript in preparation; Jacq 2005; Jacq \& Sidwell 1999; Long \& Zheng 1998; Matisoff 1973a; Premsrirat 1987; Saul \& Wilson 1980; O.J. Svantesson, A. Holmer \& D. Tayanin, manuscript in preparation; Wang \& Zheng 1993). An important though dated bibliographical source is Huffman (1986). Linguistic journals specializing in MSEA include Mon-Khmer Studies and Languages of the Tibeto-Burman Area (compare also Fournal of Chinese Linguistics and Journal of East Asian Linguistics). Regular conferences include the Southeast Asian Linguistics Society Annual Meeting and International Conferences on Tai Studies, Thai Studies, Lao Studies, SinoTibetan Languages and Linguistics, and Austroasiatic Linguistics.

Phonological structure. Vowel phoneme systems in MSEA are large, commonly displaying nine simple vowel contrasts, usually including a high nonfront unrounded vowel and a range of complex vowel combinations (diphthongs or $/ \mathrm{VV} /$ sequences). (See Table 1, above.) Phonotactics generally work on an/initial/rhyme basis, with constraints (sometimes extreme) on permissible final segments. The languages tend toward monosyllabicity; many (mostly Mon-Khmer) languages have an initial unstressed "minor syllable" in which vocalic distinctions are neutralized (e.g., Kri kura:? "path," canam “year," nalian "eel”; N.J. Enfield, field notes, 2004). Lexical contrasts are made not only by segmental distinctions but also by distinctions in pitch contour (tone) and/or phonation type 
(register) (Henderson 1965). For a description of a typical central MSEA phonological system, see Premsrirat's (1987, pp. 7-12) grammar of Kmhmu (Northern Mon-Khmer, Laos/Thailand/Vietnam).

Going further north to Hmong-Mien, Kadai, and southern Sinitic varieties, vowel contrasts decrease in number and syllablefinal segmental contrasts dwindle, whereas distinctions in initial consonants and lexical tone increase. The variety of Miao spoken in Dananshan (Guizhou, China) has, on the one hand, nearly 50 consonants contrasting in syllable-initial position at 6 places of articulation including retroflex and uvular and, on the other hand, radical constraints on permissible syllable rhymes: only 5 simple vowels $(i, e, a, u, o)$ and only 3 vowel-consonant fi-

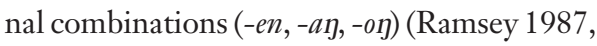
p. 282).

Most non-Mon-Khmer languages in MSEA employ tone-i.e., distinctions in syllabic pitch shape-as a means for lexical contrast. The Lao system, for example, has five tones: mid level (saw1 "rent"), high rising ( saw2 "stop"), low rising (saw3 "post"), high falling (saw4 "morning"), and low falling (saw5 "sad"). This set is of a similar size and type as those typically found in Sinitic languages and dialects. Systems with the highest number of lexical tone distinctions in the world are found to the north of MSEA, among Hmong-Mien and Tai-Kadai minority languages of southwestern China. The record number according to Ramsey (1987, p. 244) is 15 in the Kadai language, Dong (Long \& Zheng 1998, p. 31).

Many MSEA tone systems contrast syllable types not only by pronouncing them with a specific pitch contour but also with additional phonetic features such as creaky or breathy phonation or some kind of glottal constriction. Of the six tones in Vietnamese, four are defined by pitch contour alone-mid level ( $m a$ "ghost"), high rising (má "mother"), low ris-

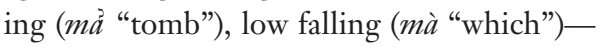
and the remaining two not only feature a specific pitch shape but also involve glottal constriction. These are a low creaky checked tone (ma $\left[\mathrm{ma}_{\sim}{ }^{11}\right]$ "rice seedling") and a highrising broken tone in which a glottal constriction occurs mid way through articulation of the rising-pitch syllable $\left(m \tilde{a}\left[\mathrm{ma}_{\sim}{ }^{2} \mathrm{a}^{25}\right]\right.$ "horse"). Glottal constriction of this sorti.e., within the syllable rhyme-is common in Mon-Khmer languages of Vietnam and Laos and has apparently diffused into neighboring languages including southern dialects of Lao and some northeastern dialects of Siamese. Another example of added phonetic features in lexical tone from a different MSEA language family is the White Hmong system. Among the language's seven lexical tones, one tone is not only low and falling in pitch but has breathy phonation. Another tone is not only low in pitch but features a glottal constriction (Ratliff 1992, p. 11).

If a given MSEA language does not employ tone for lexical contrast, it will utilize some other manifestation of phonation distinction, such as a voice register system (e.g., distinguishing between syllables with breathy voice and clear voice), or a complex vowel system, which results historically from a register system (Matisoff 2001, Thurgood 1999). Premsrirat's (1987) description of a variety of Kmhmu spoken in northern Thailand notes (p. 19) that analysts disagree as to whether the operative distinction is one of tone (where pitch makes the difference) or register (where phonation type makes the difference). When both specific pitch shape and specific phonation type are consistently present, it may be that the analyst's choice is arbitrary.

Morphological structure. MSEA languages are the closest we have to what Sapir (1921) dubbed isolating and analytic morphological type. These are languages in which the number of morphemes per word approaches one, morphemes are modified neither by affixes nor internal changes, and the basic unit for the productive construction of meaningful complexes is the phrase, not the 
word. No language purely embodies this ideal, not even Sinitic, which Sapir said "does not combine concepts into single words at all” (Sapir 1921, p. 128). Sapir's claim is now known to be an overstatement (Kratochvil 1968, Packard 2000).

In no MSEA language are clausal heads or dependents morphologically marked for argument structure relations-i.e., there is neither case-marking nor agreement. Although it is often presumed that in isolating languages the functions of such morphological marking are performed by constituent order, there is considerable within-language constituent order variability. The typical MSEA language combines widespread noun phrase ellipsis (of definite arguments) with noun phrase movement (into clause-external positions like topic), resulting in great indeterminacy of surface sequences. The information required for resolving grammatical relations is normally available from verb semantics, topic continuity, and pragmatic expectation (demonstrating the redundancy of often baroque morphology in other types of languages).

MSEA languages lack inflectional categories like tense, number, and gender. Aspectual distinctions like current relevance, irrealis modality, and imperfective aspect are marked using particles and coverbs, or the like, in complex verbal phrases. A general outcome of the isolating/analytic profile of MSEA morphosyntax is the appropriation of open-class items such as nouns and verbs for closed-class grammatical functions in specific constructional formats (Enfield 2005b). Certain items will have multiple functions, for example both as regular verbs in regular verb contexts (e.g., "acquire," "finish," "exceed," "strike," "give," and "take") and as grammatical markers in other contexts (for example, in aspectual constructions, comparative constructions, adversative passive constructions, and valencechanging constructions) (Ansaldo 1999, Clark \& Prasithrathsint 1985, Enfield 2002c, Kölver 1991). Other items will function both as regular nouns (e.g., "face," "back") and as loca- tive prepositions (Bisang 1996). A lack of explicit morphology is also observed in complex constructions such as subordinate clause constructions and relativization. MSEA languages do not use morphological distinctions like verb finiteness to indicate such relations within a clause. Phrase-level constituent order is usually doing the work.

Not all MSEA languages lack derivational morphology entirely. Mon-Khmer languages have derivational morphology of varying richness and productivity. A rich system of derivational morphology is found in Semelai (Aslian, Mon-Khmer) spoken in peninsular Malaysia (Kruspe 2004). In Mon-Khmer languages of MSEA further north, such morphology is disappearing or gone. Kmhmu has derivational affixes (such as causative infixes), which appear to be productive (Premsrirat 1987). In Khmer, derivational morphology of this kind is visible (i.e., historically vestigial) but no longer productive (Huffman 1970, pp. 311). [See also Thomas (1969) on the eastern MonKhmer language Chrau, spoken in Vietnam.] Functions of Khmer prefixes and infixes include valence increase [s?aat "to be clean" $\rightarrow$ sampaat "to clean (sth.)"], adjective derivation ( rocal derivation (kham "to bite" $\rightarrow$ prakham "to bite each other"), and nominal derivation (cuəl "to rent" $\rightarrow$ cnuəl "rent"). Nothing like this is found natively in Sinitic or Tai, although some scholars argue that morphology of this kind previously existed in these language groups (e.g., Sagart 2001). In some cases, lexical borrowing from Mon-Khmer has brought visible (but nonproductive) morphology into languages of other families. In Siamese, for example, there are pairs of words like chan "to eat (of monks)" and canghan "to ritually offer food to monks," or truat "inspect" and tamruat "police officer," where the complex forms were borrowed from Khmer with the $-a N$ infix already in place. As in the source language Khmer, this infix is not synchronically productive in Siamese. Morphology of this kind has been driven out of Vietnamese altogether in its long process of 
de-Mon-Khmer-ization (although there may be evidence in the modern phonology of erstwhile affixes).

Elaborative lexicon and morphology. An underappreciated area of morpholexical structure in MSEA languages is the set of resources for elaborative, rhyming, or alliterative expression. Many MSEA languages feature a word class of expressives (Diffloth 1972) or ideophones (Voetz \& Kilian-Hatz 2001). These are rhyming/alliterative sound symbolic items with vivid experiential-imagic meanings (e.g., Lao qêêk -lêêk4 "lying askew like someone asleep in an awkward position," quj1-luj1 "chubby like a fat baby," qùng1lùng1 "swollen up, of noodles left too long in soup before being eaten"). Expressives have been described in Mon-Khmer languages such as Semai and Surin Khmer (Diffloth $1972,1976,2001)$ as well as neighboring languages like Siamese and Lao (Crisfield 1978). These expressions can be regarded as morphologically complex (consider the $l$-segment in the Lao examples just cited). However, comparative work is difficult owing to the lack of descriptive material. [In several Lao grammars, expressives are not even recognized as a word class (e.g., Hospitalier 1937, Reinhorn 1980).]

Another kind of elaborative morphological pattern in MSEA is exemplified by a productive associative expression in Lao, usually formed from a noun by reduplication with regular vowel mutation in the repeated syllable. For example, the high back vowel in patuu "door" is reproduced as a front vowel at same height, giving patuu patii "doors and stuff like that (i.e., window frames, shutters, etc.)." Another example is cò̀k5 cèè 5 "cups/glasses and stuff like that," derived from cò̀k 5 "cup/glass." A huge system of such patterns is found in Vietnamese (Thompson 1987 [1965]), despite its status as an archetypal morphology-poor language. Other MSEA languages use tone for similar types of morphological derivation [e.g., White Hmong (Ratliff 1992) and Cantonese (Matthews \& Yip 1994)].
The productivity and internal complexity of elaborative morpholexicon in MSEA languages should weaken claims that these languages lack morphology. One just has to know where to look.

Nominal structure. Nouns in MSEA languages are not inflected (e.g., for number, gender, or case). There is widespread ellipsis of definite arguments, regardless of grammatical role. Pronoun systems often encode distinctions of politeness comparable with European tu/vous systems, but with more distinctions, made in first- and third-person reference as well as second (Cooke 1968). Nominal derivation is mostly by compounding. In numeration and other kinds of constructions involving quantification and nominal modification, MSEA languages widely use numeral classifier systems. [On classifiers in MSEA languages generally, see Bisang (1999) and references in Aikhenvald (2000).] Languagespecific studies include Carpenter (1986), Daley (1996), Enfield (2004), and Hundius \& Kölver (1983). The existence of numeral classifiers is typologically related to the less hierarchical and more appositional structure of noun phrases in these languages (Gil 1987).

\section{Clausal/sentential organization. MSEA}

languages show mostly verb-object order in the clause (although Tibeto-Burman languages are mostly verb final). Further implied constituent orderings à la Greenberg (1966) are not consistent across MSEA languages. For example, although both Tai and Sinitic languages show verb-object order, Tai languages tend to have noun-modifier order in noun phrases, whereas Sinitic languages mostly have modifier-noun order (Enfield 2003b, pp. 58-61).

MSEA languages widely feature topiccomment organization, an alternative mode of structuring sentences to the subject prominence more familiar from European languages (Fuller 1985, Li \& Thompson 1976). In this type of sentence a topical nominal appears in initial position, external to the clause 
Linguistic area: a geographical region in which neighboring languages belonging to different language families show a significant set of structural properties in common, where the commonalities in structure are due to historical contact between speakers of the languages, and where the shared structural properties are not found in languages immediately outside the area (ideally where these include languages belonging to the same families as those spoken inside the area). that follows but semantically connected in that it sets the scope of what is to come. An example from Siamese is talaat nii, plaa maj phèeng (market this, fish not expensive) "(At) this market, fish is not expensive." Topic prominence goes well beyond MSEA, occurring throughout East Asia and beyond.

A third feature of sentential organization in MSEA is the use of sentence-final particles as a basic mode of distinguishing illocutionary force at the utterance level (Crisfield 1974, Luke 1990). A basic proposition such as Lao man 2 kin 3 nam 4 (3sg drink water) can be made into questions or statements of various kinds by adding one of a large set of monosyllabic final particles at the right border of the clausal core. For example, man 2 kin 3 nam 4 bò̀3 (3sg drink water PCL) "Will he drink water?"; man2 kin3 nam4 vaa3 (3sg drink water PCL); “Oh, he'll drink water, will he?”; man2 kin3 nam4 dêj2 (3sg drink water PCL) "He'll drink water, you know"; man 2 kin 3 nam 4 dee 4 (3sg drink water PCL) "He'll drink water, y' hear!"

Typology and description of MSEA languages. MSEA languages have much in common beyond the features reviewed here. Many basic principles of lexico-grammatical organization are alike, and many candidate domains can be systematically compared on the basis of more focused primary research, beyond the kinds of information available in published grammars. The current descriptive bias is toward the national, lowland languages, with available documentation for only a fraction of the minority languages of Cambodia, Thailand, Laos, and Vietnam. Comparison of deeper organizational principles (especially in semantics and pragmatics) across MSEA languages is still pending because most languages of the area are yet to be well described or described at all.

\section{AREAL LINGUISTICS}

Areal linguistics seeks to understand situations of extensive structural parallelism in lan- guages of different families spoken in the same place, like the one described here for MSEA (Aikhenvald \& Dixon 2001, Dahl 2001, Thomason 2001). Sites of empirical research in areal linguistics include India (Emeneau 1956, Masica 1976), the Balkans (Joseph 1983), Northern California (Haas 1978, part 3; Sherzer 1973), Arnhem Land (Heath 1978), Ethiopia (Ferguson 1976, Tosco 2000), Western Europe (Haspelmath 1998, 2001), the Circum-Baltic area (Dahl \& KoptjevskajaTamm 2001), Australia (Dixon 2001), and the Vaupes region of Northwest Amazonia (Aikhenvald 2002). Studies of MSEA languages from an areal perspective include Alves (1995), Ansaldo (1999), Bisang (1991, 1996, 1999), Chappell (2001a,b), Clark (1985, 1989, 1996), Clark \& Prasithrathsint (1985), Enfield (2001b; 2002a; 2003b; 2005b,c) Huffman (1973), Matisoff (1978; 1986; 1991a,b; 2001), Oey (1990), Sybesma (2004).

\section{Linguistic Areas}

That linguistic structure can diffuse and thereby permeate genealogical boundaries between languages is fundamental to the idea of a linguistic area or Sprachbund (Trubetzkoy 1930) (compare Aikhenvald \& Dixon 2001, Emeneau 1956, Masica 1976, Sherzer 1973, Thomason 2001). A linguistic area is defined as a geographical region in which neighboring languages belonging to different language families show a significant set of structural properties in common, where the commonality in structure is due to contact and where the shared structural properties are not found in languages immediately outside the area (ideally where these include languages belonging to the same families as those spoken inside the area). Applying the definition raises many questions. At what level do we say that different languages belong to different families? Is it enough that they are of different subgroups? What degree of structural parallelism counts as significant? How many properties need to be shared? Which ones count? Can we rank their importance? Should typologically 
unusual features take priority when typologically common features may just as well be diffused? How significant is it that two languages share a handful of features, given thousands of differences?

Despite much discussion of these questions, there are few good answers. Some scholars continue to refine and defend more or less rigorous definitions of linguistic area, using these as a basis to appraise existing attempts to establish such areas (Campbell et al. 1986, Haspelmath 2004, Tosco 2000). Others suggest specific solutions to methodological problems. Van der Auwera (1998) advocates dropping the use of isoglosses, which map the areal distribution of individual linguistic features, in favor of isopleths, which map a raw number of features for each language from a predetermined list defining a focal language for that area (compare Koptjevskaja-Tamm \& Wälchli 2001). Unresolved is the question of what determines the critical pregiven list of defining features. How to decide-on principled grounds-which MSEA language would be the archetypal, defining one?

Despite the important definitional, criterial, and methodological questions, there is a lack of explicit motivation for focusing research on the linguistic area idea in particular, rather than on the more general phenomenon of areal diffusion. Some suggest abandoning the question of whether a given place is a linguistic area, proposing instead to focus on the nature of areal diffusion and its effects wherever these are observed (Dahl 2001, Muysken 2000, Stolz 2002). In their masterful overview of the Circum-Baltic languages, Koptjevskaja-Tamm \& Wälchli (2001, p. 624) "doubt whether the notion of Sprachbund in any of its less trivial interpretations does justice to an area of such historical and linguistic complexity." The same can be said with regard to MSEA. An emerging view is that defining the notion linguistic area in general or in specific cases "will probably never come to a really satisfying conclusion" (Stolz 2002, p. 259).
Ideological and personal considerations. There are political, ideological, and even personal aspects to a researcher's claim that a geographical area is a unified linguistic area. Tosco (2000) describes the cultural and sociopolitical context of Ethiopia as a nation at the time Ferguson proposed an Ethiopian linguistic area (Ferguson 1970, 1976). He suggests that a prevailing political and cultural ideology of Ethiopia as a unified multiethnic society may have been responsible for encouraging the linguist to look for, and see, evidence of a linguistic area corresponding to the (then) political unit Ethiopia. Tosco offers this analysis as a possible explanation for Ferguson's allegedly going beyond the data to arrive at a conclusion that may have been desirable for ideological rather than scientific reasons.

By contrast, no contemporary political or cultural ideology would be served by a characterization of MSEA as a unified area of linguistic or other convergence. To the contrary, there are ideologies that work to maintain difference. Unlike Ferguson's Ethiopia, MSEA is carved up by well-entrenched international borders. Salient and emblematic differences between languages of modern MSEA make it difficult for lay people to see the extensive formal similarities. For example, although a genealogical relationship between Vietnamese and Khmer is universally accepted by linguists, superficial yet highly visible differences between the languages (e.g., Vietnamese written in a roman script, Khmer in an Indic script; Vietnamese a tone language, Khmer not) can obscure the fact that the two languages spring from the same source. The societies in which these two languages are spoken are divided by the sinosphere/indosphere distinction, and further by significant historical sociopolitical enmity. Siamese and Khmer, by comparison, are not genealogically related, but a long cultural affinity between Siamese- and Khmerspeaking societies, associated with superficial but salient similarities between the languages [e.g., Indic script and vocabulary as well as shared syntactic and semantic structure 
(Huffman 1973)], has caused them to look very much alike. ${ }^{1}$

It may be MSEA's residual status that encourages the idea that it is "an area." MSEA is perhaps the leftover zone at the center of three culturally, politically, and religiously coherent unities: the Austronesian island world to the south and east, the South Asian world to the west, and the Chinese world to the north.

\section{Inheritance versus Diffusion}

A traditional view of linguistic relatedness, based on the Indo-European roots of historical and comparative linguistics, sees languages evolving by speciation-dividing, innovating, and becoming separate and different languages over time. Darwin's genealogical tree fit this model like a glove. But challenges arose when researchers encountered different language situations in new parts of the world. Studying Native American languages of the North Pacific Coast convinced Boas and his students that a language could acquire new grammatical structure from diffusion caused by language contact (Sherzer 1973, p. 752). Sapir wrote of "the grammatic, not merely lexical, influence that dialects of one linguistic stock may exert on geographically contiguous dialects of a fundamentally distinct stock" (Sapir 1907, p. 542). [For further historical background to the intellectual insight that grammatical structure can diffuse by contact, see Campbell et al. (1986, p. 531) and Emeneau (1956, pp. 3-5).]

At the time that Boas and company were documenting structural diffusion among Native American languages, French scholars were pondering the genealogical affinity

\footnotetext{
${ }^{1}$ However, for ideological reasons, many Siamese speakers are disturbed by claims of overly close relatedness between Siamese and Khmer language or society. Many Thai have difficulty stomaching the idea that their ancestors may have been as much Khmer as Thai, as suggested by Khanittanan's hypothesis that early Thai society was a site of stable bilingualism (Khanittanan 2001).
}

of Vietnamese, now known to be a MonKhmer language. Their dilemma, first posed by Maspero (1912), was whether to place Vietnamese together with Mon-Khmer languages, as suggested by its basic vocabulary, or with Tai (or Sinitic) languages, as suggested by its having phonological tone (Matisoff 1973b). Vietnamese phonology is radically different from its Mon-Khmer cousins, with a full-blown lexical tone system and strict monosyllabicity (Gage 1985). Maspero concluded against the idea that Vietnamese was a Mon-Khmer language on the basis of his assumption that it was impossible for a language to have tone other than by inheritance from an ancestor language. Decades later, Haudricourt (1954) came to the opposite conclusion by showing how tones could have arisen independently in Vietnamese, thereby showing it to be classifiable as a Mon-Khmer language.

Critical in this account of tonogenesis is the idea that when multiple phonetic features (e.g., pitch and initial consonant voicing) consistently co-occur in a specific type of syllable, a shift can take place from one feature to the other in terms of which one is responsible for the contrastive load. Thus, when elements of segmental phonology, such as voicing of an initial segment or aspiration of a final segment, affect pitch in the phonetics, pitch may take on the phonological role of signaling lexical contrast in the syllable and then allow the original segmental distinction to be lost, giving rise to lexical contrast by pitch alonei.e., tone. [See Norman (1988, p. 54ff) for a discussion of Vietnamese tonogenesis in the context of Sinitic and Tai (see also Gedney 1989).]

The same basic process gives rise to voice register systems, widely observed in MonKhmer languages of MSEA(Henderson 1965, Jenner 1974). Distinctions in initial consonant voicing can be associated with phonetic differences in phonation type or vowel quality. In turn, these phonation or vocalic differences can then take on the load of lexical contrast, allowing the original voicing distinction 
to be lost. For example, a historical contrast in initial voicing like $p a$ versus $b a$ can correspond to a modern contrast by vowel phonation type alone, e.g., $p a_{\text {'clear' }}$ versus $p a^{\text {'breathy }}$ ' A development arising, in turn, from a register distinction of this kind is fractionation of the system of vowel quality distinctions. For example, breathy phonation may affect the phonetic quality of a vowel and this vowel quality distinction may then take up a contrastive load, which would allow the phonation distinction to disappear. Thus, $p a_{c l e a r}$ versus $p a_{b r e a t b y}$ becomes $p a_{c l e a r}$ versus $p^{j} a_{\text {breatby }}$, and finally $p a$ versus $p^{j} a$.

These processes can be observed at various stages in modern languages of the eastern Mon-Khmer branch [e.g., Khmer (Headley 1998, p. 23) and many Katuic languages]. Minority Vietic languages spoken in the highlands of central Laos and Vietnam are on a cusp in this cycle between register, tone, and split-vowel systems. In Kri (Vietic, central Laos), for example, voice register is the operative phonological distinction, but for most vowels there are distinct quality differences associated with the two registers [e.g., clear [?ata:m] /Rata:m/ "crab" versus breathy [mat $\left.{ }^{\text {u}} a: m\right]$ ] /matạ:m/ "son-in-law” (N.J. Enfield, field notes, 2004]. For other Vietic languages, the same distinction is marked by phonological tone (Alves 1997).

Not only did the discovery of tonogenesis in Vietnamese show that a language could independently develop a tone system, but also it suggested that such a system could arise via language contact ( $\mathrm{Li} \mathrm{1986,}$ Thurgood 1996). This dramatically demonstrated the possibility of contact-related diffusion of the type of feature previously thought to have been locked in a language's "genetic code." Such radical overhaul of internal structure by external contact is what transformed Vietnamese into the black sheep of the MonKhmer family, and Chamic into the black sheep of the Austronesian family. These thoroughgoing effects invite us to question the whole idea of genealogical relations among languages.
A new standard view: best of both worlds? Acknowledgment of the extensive contactinduced permeability of language structure has led to a view that the genealogical tree model of language relatedness is not always an appropriate mode of representation or analysis. However, scholars also generally agree that the model should nevertheless be maintained and employed where it does appear to apply. A new research objective is thus to characterize properly the interface between structural/internal and social/external processes by which linguistic systems become similar or different.

According to Thomason \& Kaufman (1988), one type of exceptional situation in which the genealogical tree model is not applicable is the type of dramatic social upheaval associated with emergence of creoles and other mixed languages. In these cases, the absence of normal transmission in language socialization results in the emergence of languages for which no single language can be said to be the parent. Another case of nongenealogical language relatedness is Dixon's (1997) equilibrium state, in which long periods of social stability and associated multilateral diffusion in a multi-language area make it impossible for the latter-day researcher to assess whether languages' sharing of a trait is due to borrowing or to common inheritance. Between the extremes of Dixon's long-term social harmony and Thomason \& Kaufman's (1988) utter social chaos is a default model of orderly splitting and separating of speech communities arising from socio-historical punctuation, where regular processes of internal structural change give rise to language speciation via inheritance of different innovated features along different lines of descent.

Even in a textbook genealogical language family situation, borrowing and diffusion through contact with neighboring language communities will permeate a language's "genetic code." Because social factors are always at work, the external or diffusional dimension to language change and structuration warrants careful social analysis (Enfield 2003b;
Normal

transmission:

occurs when, in a

relatively stable

social situation, children are able to learn essentially the same complete set of linguistic components (phonological, lexical, morphosyntactic, semantic, idiomatic, etc.) as found in the speech of their parents and the community at large. 
Le Page \& Tabouret-Keller 1985; Milroy 1980; Ross 2001, 2003; Thomason \& Kaufman 1988; Weinreich et al. 1968). Among recent research addressing this, Ross analyzes areal linguistic relationships in Island Melanesia with reference to distinctions in the structure and nature of neighboring societies and interethnolinguistic relations (where communities may be tight-knit or loose knit, more or less open, etc.), operationalizing some potentially meaningful social differences with specific predictions as to structural consequences (Ross 2001, 2003). Aikhenvald's (2002) study of language contact in northwest Amazonia includes careful analysis of the ethnography of multilingualism. These studies are among the few available that genuinely address the need for greater rigor in exploring the language-society nexus and assessing the ways in which ground-level social processes can affect or determine linguistic relatedness.

Within the now-generally-agreed-upon position that there are both internal/ structural and external/social factors at play in language structuration and relatedness, the main tension concerns which of the two related dimensions to emphasize. For some scholars, socially driven diffusion has virtually unlimited power. Thomason (2000a) writes that social factors can override any type of linguistic structural constraint, and prediction of linguistic change is therefore impossible. There is so little evidence of absolute linguistic constraints on change that "the burden of proof should surely be on those who would claim the existence of linguistic constraints on change, whether internally motivated or externally motivated" (Thomason 2000b). "Any linguistic feature can be transferred from any language to any other language" (Thomason \& Kaufman 1988, p. 14). Some find this view disturbing, insisting that linguistic structure can and does impose constraints on possible outcomes of contact-induced change (Aikhenvald 2002, p. 2), or calling for more positive, clear, and testable hypotheses as to how social and structural pro- cesses may constrain each other (Haspelmath 2004).

Underlying this disagreement is a deeper issue. Although many scholars agree that the genealogical model should be maintained and employed in appropriate circumstances, they differ as to whether the model should be viewed as a reasonable theory or merely a reasonable methodology (Thomason \& Kaufman 1988, p. 3). The profound theoretical challenge posed by the phenomenon of areal diffusion for the genealogical model of language relatedness is yet to be appreciated.

\section{The Lesson of Areal Linguistics: Language as a Unit-Based Population Phenomenon}

Careful consideration of what it means to acknowledge the possibility of permeation of the genealogical tree model by social contact gives reason to view all language situations in a new way. A unit-based approach to processes of language contact and change is needed, where the units of relevance are individual linguistic items and individual speakers. This provides for a unified account of contact and change, preferable to the less parsimonious double analytical machinery currently required for simultaneously modeling social/external processes of linguistic structuration while honoring and maintaining structural/internal linguistic principles of change and genealogical inheritance.

The genealogical view of language relatedness entails an essentialism of the kind generally rejected in current anthropology. This view overlooks the fact that the evolution of large-scale social phenomena such as languages is a unit-level, population-based process. As Laland \& Odling-Smee (2000, p. 121) put it, "biologists and human scientists alike will not be able to understand the evolution of culture unless they are prepared to break down the 'complex whole' into conceptually and analytically manageable units" (see Hedström \& Swedberg 1998, Nettle 1997). Languages are not entities but aggregates of 
entities. Their appearance as essential wholes is a product of what Thomason \& Kaufman (1988) refer to as normal transmission in language socialization, where "what is transmitted is an entire language - that is, a complex set of interrelated lexical, phonological, morphosyntactic, and semantic structures" (p. 11). This passing on of the whole package-which takes years and many thousands if not millions of independent interactions-gives the appearance of historical continuity of the language as a unit, just as if "a daughter language in a family tree is a changed later form of its single parent language" (Thomason \& Kaufman 1988, p. 11). But the convenient figurative description of this as a case of "one language parenting another" is false.

In reality, all processes resulting in language relatedness are social diffusional processes, where the relevant units are linguistic items (Hudson 1996, Nettle 1999) or "linguemes" (Croft 2000), along the same lines as, but at finer granularity than, Thomason \& Kaufman's different "subsystems" or "parts of the language." Although integrated into a structured system in the cognition of individual speakers, a language's constituent items are separable, each with their own careers across the community of minds. Despite each individual's personal creation and potential transformation of each item (i.e., as a category in one's own head) in constructing and incrementing our own idiolects, we nevertheless, in collaboration with our social associates, cause whole bundles of such items to persist with stability in populations (Keller 1994, Sperber 1985).

Units of language do not randomly spread through communities. They cluster such that the inventories of items belonging to individuals in closely associating social groups bundle in the same ways - i.e., people "speak the same language." A change in language is a change in social practice convention, and this change is possible only by means of successful social diffusion of an innovation, just like a new fashion or a virus. A realistic account of language change, which applies equally to "internal" and "external" processes, is an epidemiology of linguistic representations (Enfield 2003b, pp. 8-19; Sperber 1985). The key elements are behavioral innovation, the individual's exposure to the innovation, his or her adoption and reproduction of the innovation, and critical mass adoption at the population level, leading to it becoming a community convention (i.e., no longer an innovation).

Many factors affect the course of events leading to successful diffusion of innovation (Rogers 1995). For both sociological and personal reasons, different people have different likelihoods of exposure to a given innovation. They may have higher or lower mobility implied by their mode of livelihood. They may be personally more or less gregarious. Having been exposed to a new practice, an individual may or may not adopt and reproduce it. An innovation may be more or less attractive to potential practitioners. It might have intrinsically useful properties, for example, giving one a new and convenient way of saying something not easily said before. It may allow one to display social identification with an outside individual or group who employs the practice. We know from sociolinguistic research that many items in circulation in a single community may be recognized by people of all different social identities (gender, race, class, age) but are used only by a subset. In MSEA, for example, Lao speakers understand closely related and prestigious Siamese but cannot go too far in using many of the language's elements while speaking Lao because to do so would be strongly identified as "not Lao" (Enfield 1999). To use a new expression is to be different from one's peers, and cultures differ as to the degree such individual expression is valued or sanctioned. The kinds of prescriptive and proscriptive language ideologies Aikhenvald describes for the language contact situation in northwest Amazonia (Aikhenvald 2002) are critical here. Language ideology works at ground level and in real time, licensing a usage or a sanction for a usage, on particular occasions of face-to-face interaction. It can account for emotional responses to such sanctions, real or anticipated. 
BROADENING THE RANGE OF DIFFUSIBLE PHENOMENA: TOWARD AREAL SEMIOTICS

Areal linguistics can be approached as part of the broader phenomenon of socio-historical diffusion of innovation in cultural practice (Rogers 1995). Even within the semiotic and cultural phenomena most closely tied to linguistic structure, little is known about the geographical distribution of variation. The domain of lexical semantics is beginning to receive some attention here, beginning with Matisoff's (1978) pioneering exploration of "variational semantics" in Tibeto-Burman and other MSEA languages (see also Ameka \& Wilkins 1996, Evans \& Wilkins 2000, Wilkins 1996). Beyond the linguistic "code" are the processes underlying inferential pragmatics (Grice 1989). These principles are thought not to vary cross-linguistically (Levinson 2000), but the shared ethnographic background that feeds into the logic of implicature (Levinson 1995) and which is eventually enshrined in grammatical structure (Enfield 2002b, Evans 2003, Simpson 2002)—certainly does show areal variability. So too do aspects of interactional structure, not only in speech routines such as greetings or incantations, but in the structural organization of casual conversation, including mechanisms for repair of errors/ inappropriatenesses, properties of question-answer sequences, turns at talk, discourse markers, and the bodily orientation of speakers in interaction (see Enfield 2003a, Moerman 1988 , for work in MSEA). Also closely related to language, and areally variable in form and function, is cospeech hand gesture (Kendon 2004, McNeill 1992; see Enfield 2001a, 2005a for work in MSEA). not result in a new convention unless there is a critical mass adoption of the innovation by others in the group, such that the balance tips from the practice being new to being normal. The critical difference between an innovation succeeding or failing to take hold can be as minor as the flutter of a butterfly's wing, equally unpredictable and equally untraceable in retrospect. This is because social change is sociometrically emergent. The contribution of individual elements in the system is key (Gladwell 2000; Granovetter 1973; Schelling 1971, 1978). Granovetter (1978) provides a simple illustration in his threshold model of collective behavior. Suppose you have 100 people together in a public place. One of these people (an innovator) throws a brick through a window. Suppose the other individuals in the group are ranked on a scale of increasing thresholds for joining in such behavior. If one person (an early adopter) has a threshold of 1 (i.e., will start throwing bricks through windows as long as at least one other person is already doing it), the next has a threshold of 2 , the next a threshold of 3 , and so on until the last with a threshold of 99, then a full-scale riot will occur and everyone will be throwing bricks. But if, say, the person with a threshold of 1 stayed home on this occasion, or we raised this person's threshold a single notch to 2 , our innovatively thrown brick would have led to nothing. In riot behavior, as in other cases of the large-scale adoption of social practices instigated by an innovative few (e.g., contactinduced language change), any number of very small things can each make a very big difference. This makes it difficult to be confident about the possibility of figuring out in retrospect (e.g., 2000 years later) just why a certain innovation took hold in one case and not in another (Enfield 2003b, p. 365).

A unit-based memetic account matches the facts of linguistic processes on the ground and in real time because it works with units that have ontological plausibility: individual speakers, individual utterances, cognitive representations of those utterances by 
individual speakers, and action decisions based on social identity. This, however, does not call for pessimism in research on linguistic diffusion. I mention here three directions in research that are compatible with a unitbased view of contact and areal diffusion and which promise both theoretical and empirical advances in the study of how areal linguistic phenomena actually come about.

First, computer simulations of communities of individuals and their economies of linguistic items (Hurford et al. 1998, Hutchins \& Hazlehurst 1995, Nettle 1999) allow us to model interactions within populations of mobile, socially associating people and populations of linguistic signs. These studies may reveal (a) how such interactions result in the aggregation of these populations into coherent social and semiotic systems with the appearance of essential wholes, and $(b)$ the principles (if any) governing the greater or lesser permeability of these systems when in contact with other such systems.

Second, controlled psycholinguistic experiments on the emergence of communicative convention within groups (see Clark \& Wilkes-Gibbs 1986, Garrod \& Anderson 1987, Garrod \& Doherty 1994, Schober \& Clark 1989) allow control and manipulation of factors hypothesized to be operative in the successful diffusion of innovation. These factors include individuals' positions in social networks, personality types, strength of social ties, and extent of exposure to innovations.

Third, the most challenging, yet most important and potentially telling, work to be done is the fine-grained ethnographic if not biographic work we wish had been conducted in the historical contexts we are now trying to reconstruct-i.e., detailed analysis of individuals' connectedness within social networks, their social status, patterns of exposure to innovations, linguistic and social ideologies, speech practices, etc. (Milroy 1980). Such work will be invaluable to future areal linguistic researchers.
Language change by contact or otherwise is a process of social diffusion. The standard analytical distinction between internal and external linguistic mechanisms diverts attention from the fact that these are instances of the same process: the diffusion of cultural innovation in human populations. Whether an innovation actually takes off and becomes convention is a function of the many and varied factors that constitute a sociometric epidemiology of linguistic and other representations. When considering past societies, we might know something about the relevant factors-for example, relative mobility of certain groups or subgroups, or likely degree of utility of an innovation-but equally critical factors like individual personality differences or individuals' positions in social networks will be unknown and may be unknowable. This conclusion is expected, given that linguistic change is a chaotic and airborne process involving millions of entities and momentaneous events any of which may have farreaching consequences.

\section{CONCLUSION}

Mainland Southeast Asia is home to hundreds of languages from five different language families spoken virtually on top of each other. Extensive diffusional influence due to historical social contact has led to widespread similarity in structure. Developing our understanding of areal linguistics in MSEA depends first on primary linguistic and sociolinguistic description-we currently lack adequate descriptive materials for most languages and language situations of the area. In addition, there are theoretical and methodological advances in the offing. Areal linguistics in MSEA and elsewhere in the world will acquire the direction it needs when we take seriously the status of language as one manifestation of the human capacity for culture-identifiably group-specific, psychologically real, and distributed across populations of mobile individuals. 


\section{SUMMARY POINTS}

1. MSEA is a site of long-term contact between languages of several major language families. This contact has resulted in extensive parallels in linguistic structure, making MSEA an illustrative case study for areal linguistics.

2. The traditional notion that certain geographical areas are "linguistic areas" is problematic for a number of reasons. There is inconsistency among criteria for defining "area-hood." There are potential biases in diagnosing "areas," for instance owing to constraints on the analyst's breadth of view or to political and economic ideologies. Problems such as these have resulted in a movement to abandon research on "linguistic areas" in favor of research on areal linguistics in general.

3. All language change, whether by "genealogical inheritance" or "areal diffusion," is conducted by a process of social diffusion of innovation. Once this is acknowledged, the analytical distinction between inheritance and diffusion begins to crumble. Nevertheless, the genealogical method remains a useful descriptive technique.

4. Areal linguistics invites us to revise our understanding of the ontology of languages and their historical evolution, showing that the only units one needs to posit as playing a causal role are individual speakers and individual linguistic items. These unit types are mobile or detachable with respect to the populations they inhabit, arguing against essentialism in both linguistic and sociocultural systems.

\section{FUTURE DIRECTIONS/UNRESOLVED ISSUES}

1. The puzzles of language contact and linguistic diffusion in MSEA will not be solved until extensive and detailed empirical field work is carried out on the linguistic, cultural, and social systems of the area.

2. Computational modeling of processes of language contact, inheritance, and diffusion will allow analysts to explore theories of linguistic diffusion and change in powerful new ways. These promising techniques are still in the early stages of exploration.

3. Will the questions of areal linguistics remain confined to the questions of traditional linguistic typology? Areal linguistic phenomena present a valuable opportunity to see language in its larger context, connecting to research in anthropology (ethnographic background, human socio-historical activity), sociology (diffusion of innovation, the micro-macro relation, ethnic identity), and psychology (the dynamic relation between large-scale public conventions and individual mental representations).

4. Areal linguistics presents significant challenges for standard understandings of the ontology of language from both spatial and temporal perspectives. Scholars of language need to work through the implications of the view that "the language" and "the community" are incoherent as units of analysis for causal processes in the historical and areal trajectories of language diffusion and change.

\section{ACKNOWLEDGMENTS}

This review is dedicated to Gérard Diffloth, with thanks for all he has taught me about the mainland Southeast Asia area. I gratefully acknowledge the following people for their generous 
comments on this review and/or discussion of the ideas in it. Possibly against my better judgment, I have not always taken these people's good advice: Felix Ameka, Balthasar Bickel, Niclas Burenhult, Östen Dahl, Gérard Diffloth, Nick Evans, Martin Haspelmath, Maria KoptjevskajaTamm, Steve Levinson, Malcolm Ross, Rachel Selbach, and Gunter Senft. I also thank the Max Planck Society for its support of this research.

\section{LITERATURE CITED}

Aikhenvald A, Dixon RMW, eds. 2001. Areal Diffusion and Genetic Inberitance: Problems in Comparative Linguistics. Oxford: Oxford Univ. Press

Aikhenvald AY. 2000. Classifiers: A Typology of Noun Categorization Devices. Oxford: Oxford Univ. Press

Aikhenvald AY. 2002. Language Contact in Amazonia. Oxford: Oxford Univ. Press

Alves MJ. 1995. The Vietnamese linguistic belt buckle: an example of Sprachbund in Southeast Asia. In Linguistics and Language Teaching: Proceedings, ed. C Reves, C Steele, CSP Wong, pp. 21-42. Manoa: Univ. Hawaii

Alves MJ. 1997. Ruc and other minor Vietic languages: linguistics strands between Vietnamese and the rest of the Mon-Khmer language family. In Papers from the Seventh Annual Meeting of the Southeast Asian Linguistics Society, ed. KL Adams, TJ Hudak, FK Lehman, pp. 3-20. Tempe, AZ: Progr. Southeast Asian Stud.

Alves MJ. 2000. A Pacoh analytic grammar. PhD thesis. Univ. Hawaii

Ansaldo U. 1999. Comparative constructions in Sinitic: areal typology and patterns of grammaticalisation. $\mathrm{PhD}$ thesis. Stockholm Univ.

Ameka FK, Wilkins DP. 1996. Semantics. In Contact Linguistics: An International Handbook of Contemporary Research, ed. H Goeble, PH Nelde, Z Stary, W Wölck, pp. 130-38. Berlin/New York: Walter de Gruyter

Ansaldo U, Matthews SJ. 2001. Typical creoles and simple languages: the case of Sinitic. Linguist. Typol. 5:311-24

Bauer RS. 1996. Identifying the Tai substratum in Cantonese. In 4th International Symposium on Languages and Linguistics, Pan-Asiatic Linguistics, pp. 1806-44. Bangkok: Inst. Lang. Cult. Rural Dev., Mahidol Univ., Salaya

Bauer RS, ed. 2002. Collected Papers on Southeast Asian and Pacific Languages. Canberra: Pac. Linguist.

Benedict PK. 1972. Sino-Tibetan: A Conspectus. Cambridge: Cambridge Univ. Press

Bisang W. 1991. Verb serialization, grammaticalization and attractor positions in Chinese, Hmong, Vietnamese, Thai and Khmer. In Partizipation: Das Sprachliche Erfassen von Sachverhalten, ed. H Seiler, W Premper, pp. 509-62. Tübingen: Gunter Narr Verlag

Bisang W. 1996. Areal typology and grammaticalization: processes of grammaticalization based on nouns and verbs in South-East Asian languages. Stud. Lang. 20:519-97

Bisang W. 1999. Classifiers in East and Southeast Asian languages: counting and beyond. In Numeral Types and Changes Worldwide, ed. J Gvozdanovic, pp. 113-85. Berlin: Mouton de Gruyter

Blake B. 2001. Global trends in language. Linguistics 39:1009-28

Bradley D, ed. 1989. South-East Asian Syntax. Canberra: Pac. Linguist.

Bradley D. 1994. East and Southeast Asia. In Atlas of the World's Languages, ed. C Moseley, RE Asher, pp. 159-92. London: Routledge

Bradley D. 2003. Language and culture of minority groups. In Laos and Ethnic Minority Cultures: Promoting Heritage, ed. Y Goudineau, pp. 45-68. Paris: UNESCO a set of detailed empirical studies of the problem of distinguishing "areal" vs. "genetic" relationships between languages, with data and discussion from around the world; includes four chapters relating to MSEA. 
Budge C. 1980. Southeast Asia as a linguistic area. Master's Diss. Monash Univ., Melbourne Burusphat S, ed. 2000. Proc. Int. Conf. Tai Stud., Fuly 29-31, 1998. Bangkok: Mahidol Univ.

Campbell L, Kaufman T, Smith-Stark TC. 1986. Meso-America as a linguistic area. Language 62:530-70

Capell A. 1979. Further typological studies in Southeast Asian languages. In Southeast Asian Linguistic Studies, ed. ND Liem, pp. 1-42. Canberra: Pac. Linguist.

Carpenter K. 1986. Productivity and pragmatics of Thai classifiers. Berkeley Linguist. Soc. 12:1425

Chandler D. 1996. A History of Cambodia. Chiang Mai: Silkworm Books

Chao YR. 1968. A Grammar of Spoken Chinese. Berkeley/Los Angeles: Univ. Calif. Press

Chappell H. 2001a. Language contact and areal diffusion in Sinitic languages. See Aikhenvald \& Dixon 2001, pp. 328-57

Chappell H, ed. 2001b. Sinitic Grammar: Synchronic and Diachronic Perspectives. Oxford: Oxford Univ. Press

Clark HH, Wilkes-Gibbs D. 1986. Referring as a collaborative process. Cognition 22:1-39

Clark M. 1985. Asking questions in Hmong and other Southeast Asian languages. Linguist. Tibeto-Burman Area 8:60-67

Clark M. 1989. Hmong and areal Southeast Asia. See Bradley 1989, pp. 175-230

Clark M. 1996. Where do you feel?: stative verbs and body-part terms in Mainland Southeast Asia. In The Grammar of Inalienability, ed. H Chappell, W McGregor, pp. 529-64. Berlin: de Gruyter

Clark M, Prasithrathsint A. 1985. Synchronic lexical derivation in Southeast Asian languages. See Ratanakul et al. 1985, pp. 34-81

Comrie B, ed. 1990. The Major Languages of East and South-East Asia. London: Routledge

Condominas G. 1990. From Lawa to Mon, from Saa' to Thai. Historical and Anthropological Aspects of Southeast Asian Social Spaces. Canberra: Res. Sch. Pac. Stud., Aust. Natl. Univ.

Cooke JR. 1968. Pronominal Reference in Thai, Burmese and Vietnamese. Berkeley: Univ. Calif. Press

Crisfield AG. 1974. Lao final particles. See Nguyen 1974, pp. 41-45

Crisfield AG. 1978. Sound symbolism and the expressive words of Lao. PhD thesis. Univ. Hawaii

A provocative exploration of language change conceived as an evolutionary process; demonstrates the need for different units of analysis than are standard in the genealogical view of language.

\section{Croft W. 2000. Explaining Language Change: An Evolutionary Approach. Essex: Long-} man

Culas C, Michaud J. 2004. A contribution to the study of Hmong (Miao) migrations and history. In Hmong/Miao in Asia, ed. N Tapp, J Michaud, C Culas, G Yia Lee, pp. 61-96. Chiang Mai: Silkworm Books

Dahl Ö. 2001. Principles of areal typology. In Language Typology and Language Universals, ed. M Haspelmath, E König, W Oesterreicher, W Raible, 2:1456-70. Berlin: Mouton de Gruyter

Dahl Ö, Koptjevskaja-Tamm M, eds. 2001. The Circum-Baltic Languages: An Areal-Typological Approach. Amsterdam: Benjamins

Daley KAC. 1996. The use of classifiers in Vietnamese narrative texts. Master's Diss. Univ. Tex., Arlington

Diffloth G. 1972. Notes on expressive meaning. Chicago Linguist. Soc. 8:440-47

Diffloth G. 1974. Austro-Asiatic languages. Encycl. Br. 1974:480-84

Diffloth G. 1976. Expressives in Semai. Austroasiatic Stud. 1. Ocean. Linguist., Honolulu, Univ. Hawaii Spec. Publ. 13:249-64

Diffloth G. 2001. Les expressifs de Surin, et où cela conduit. Bull. Ecole Fr. Extrême-Orient 8:261-69 
Diffloth G, Zide N. 1992. Austro-asiatic languages. In International Encyclopedia of Linguistics, ed. W Bright, pp. 137-42. New York: Oxford Univ. Press

Diller AVN. 1988. Thai syntax and 'national grammar'. Lang. Sci. 10:273-312

Diller AVN. 1993. Diglossic grammaticality in Thai. In The Role of Theory in Language Description, ed. WA Foley, pp. 393-420. Berlin/New York: Mouton de Gruyter

Diller AVN, Edmondson J, eds. 2005. The Tai-Kadai Languages. London: RoutledgeCurzon

Diller AVN, Khanittanan W. 2002. Syntactic inquiry as a cultural activity. See Enfield 2002b, pp. 31-51

Dixon RMW. 1997. The Rise and Fall of Languages. Cambridge, UK: Cambridge Univ. Press

Dixon RMW. 2001. The Australian linguistic area. See Aikhenvald \& Dixon 2001, pp. 64-104

Edmondson JA, Solnit DB, eds. 1988. Comparative Kadai: Linguistic Studies Beyond Tai. Arlington: Summer Inst. Linguist., Univ. Tex.

Edmondson JA, Solnit DB, eds. 1997. Comparative Tai: The Tai Branch. Arlington: Summer Inst. Linguist., Univ. Tex.

Emeneau MB. 1956. India as a linguistic area. Language 32:3-16

Enfield NJ. 1999. Lao as a national language. See Evans 1999, pp. 258-90

Enfield NJ. 2001a. 'Lip-pointing'-a discussion of form and function with reference to data from Laos. Gesture 1:185-212

Enfield NJ. 2001b. On genetic and areal linguistics in mainland Southeast Asia: parallel polyfunctionality of 'acquire'. See Aikhenvald \& Dixon 2001, pp. 255-90

Enfield NJ. 2002a. Biclausal expressions of 'cause' in mainland Southeast Asia. Berkeley Linguist. Soc. 28

Enfield NJ. 2002b. Cultural logic and syntactic productivity: associated posture constructions in Lao. In Ethnosyntax: Explorations in Culture and Grammar, ed. NJ Enfield, pp. 231-58. Oxford: Oxford Univ. Press

Enfield NJ. 2002c. Functions of 'give' and 'take' in Lao complex predicates. See Bauer 2002, pp. $13-36$

Enfield NJ. 2003a. Demonstratives in space and interaction: data from Lao speakers and implications for semantic analysis. Language 79:82-117

Enfield NJ. 2003b. Linguistic Epidemiology: Semantics and Grammar of Language Contact in Mainland Southeast Asia. London: RoutledgeCurzon

Enfield NJ. 2004. Nominal classification in Lao: a sketch. Sprachtypol. Univers. 57:117-43

Enfield NJ. 2005a. The body as a cognitive artifact in kinship representations. Hand gesture diagrams by speakers of Lao. Curr. Anthropol. 46:51-81

Enfield NJ. 2005b. Heterosemy and the grammar-lexicon trade-off. In Catching Language, ed. F Ameka, A Dench, ND Evans. Berlin: Mouton de Gruyter

Evans G, ed. 1999. Laos: Culture and Society. Chiang Mai: Silkworm Books

Evans ND. 2003. Context, culture, and structuration in the languages of Australia. Annu. Rev. Anthropol. 32:13-40

Evans ND, Wilkins DP. 2000. In the mind's ear: The semantic extensions of perception verbs in Australian languages. Language 76:546-92

Ferguson CA. 1970. The Ethiopian language area. 7. Ethiop. Stud. 8:67-80

Ferguson CA. 1976. The Ethiopian language area. In Language in Ethiopia, ed. ML Bender, JD Bowen, RL Cooper, CA Ferguson, pp. 63-76. London: Oxford Univ. Press

Fuller JW. 1985. Topic and comment in Hmong. PhD thesis. Univ. Mich.

Gage WW. 1985. Vietnamese in Mon-Khmer perspective. See Ratanakul et al. 1985, pp. 493524

Garrod S, Anderson A. 1987. Saying what you mean in dialogue: a study in conceptual and semantic co-ordination. Cognition 27:181-218
A systematic comparison of a parallel pattern of lexico-grammatical polyfunctionality across some two dozen MSEA languages, with theoretical exploration of the essentially social nature of areal and historical linguistic problems. 
A definitive account of how a language can acquire the feature of lexical tone by means other than inheritance from an ancestor language, establishing beyond doubt that Vietnamese is a Mon-Khmer language and opening up the possibility that the development of lexical tone can be caused by language contact.
Garrod S, Doherty G. 1994. Conversation, co-ordination and convention: an empirical investigation of how groups establish linguistic conventions. Cognition 53:181-215

Gedney WJ. 1989. Selected Papers on Comparative Tai Studies. Ann Arbor: Cent. South and Southeast Asian Stud., Univ. Mich.

Gil D. 1987. Definiteness, noun phrase configurationality, and the count-mass distinction. In The Representation of Indefiniteness, ed. E Reuland, AGB ter Meulen, pp. 254-69. Cambridge, MA/London: MIT Press

Gilbers DG, Nerbonne J, Schaeken J, eds. Languages in Contact. Amsterdam/Atlanta, GA:Rodopi

Gladwell M. 2000. The Tipping Point: How Little Things Can Make a Big Difference. Boston: Little \& Brown

Goddard C. 2005. The Languages of East and Southeast Asia. Oxford: Oxford Univ. Press

Granovetter M. 1973. The strength of weak ties. Am. F. Sociol. 78:1360-80

Granovetter M. 1978. Threshold models of collective behaviour. Am. F. Sociol. 83:1420-43

Greenberg JH. 1966. Some universals of grammar with particular reference to the order of meaningful elements. In Universals of Language, ed. JH Greenberg, pp. 73-113. Cambridge, MA: MIT Press. 2nd ed.

Grice HP. 1989. Studies in the Way of Words. Cambridge, MA: Harvard Univ. Press

Haas MR. 1978. Language, Culture, and History: Essays by Mary R. Haas. Stanford, CA: Stanford Univ. Press

Harris JG, Chamberlain JR, eds. 1975. Studies in Tai Linguistics in Honor of William 7. Gedney. Bangkok: Cent. Inst. Engl. Lang.

Hartmann J. 1998. A linguistic geography and history of Tai Meuang-Fai (Ditch-Dike) technoculture. Lang. Linguist. 16:67-101

Haspelmath M. 1998. How young is standard average European? Lang. Sci. 20:271-87

Haspelmath M. 2001. The European linguistic area: standard average European. In Language Typology and Language Universals, ed. M Haspelmath, E König, W Oesterreicher, W Raible, pp. 1492-520. Berlin: de Gruyter

Haspelmath M. 2004. How hopeless is genealogical linguistics, and how advanced is areal linguistics? Stud. Lang. 28:209-23

Haudricourt A-G. 1954. De l'origine des tons en viêtnamien. F. Asiat. 242:69-82

Headley RK. 1998. Cham evidence for Khmer sound changes. In Further Chamic Studies (Papers in Southeast Asian Linguistics No. 15), ed. D Thomas, pp. 21-29. Canberra: Pac. Linguist.

Heath J. 1978. Linguistic Diffusion in Arnhem Land. Canberra: Aust. Inst. Aborig. Stud.

Hedström P, Swedberg R, eds. 1998. Social Mechanisms: An Analytical Approach to Social Theory. Cambridge, UK: Cambridge Univ. Press

Henderson E. 1965. The topography of certain phonetic and morphological characteristics of South East Asian languages. Lingua 15:400-34

Himmelmann NP, Adelaar A, eds. 2005. The Austronesian Languages of Asia and Madagascar. London: RoutledgeCurzon

Hospitalier JJ. 1937. Grammaire Laotienne. Paris: Imprimerie Nationale

Hudson RA. 1996. Sociolinguistics. Cambridge, MA: Cambridge Univ. Press. 2nd ed.

Huffman FE. 1970. Modern Spoken Cambodian. Ithaca, NY: Cornell Univ., Southeast Asia Program

Huffman FE. 1973. Thai and Cambodian—a case of syntactic borrowing? 7. Am. Orient. Soc. 93:488-509

Huffman FE. 1986. Bibliography and Index of Mainland Southeast Asian Languages and Linguistics. New Haven: Yale Univ. Press 
Hundius H, Kölver U. 1983. Syntax and semantics of numeral classifiers in Thai. Stud. Lang. $7: 165-214$

Hurford JR, Studdert-Kennedy M, Knight C, eds. 1998. Approaches to the Evolution of Language. Cambridge, UK: Cambridge Univ. Press

Hutchins E, Hazlehurst B. 1995. How to invent a shared lexicon: the emergence of shared form-meaning mappings in interaction. In Social Intelligence and Interaction: Expressions and Implications of the Social Bias in Human Intelligence, ed. E Goody, pp. 53-67. Cambridge, UK: Cambridge Univ. Press

Iwasaki S, Ingkaphirom P. 2005. A Reference Grammar of Thai. Cambridge, UK: Cambridge Univ. Press

Jacob JM. 1968. Introduction to Cambodian. Oxford: Oxford Univ. Press

Jacq P. 2005. A Description of Fru' (Loven); Mon-Khmer Studies Special Publication, 2 Vols. Thailand: Mahidol Univ. In press

Jacq P, Sidwell P. 1999. Sapuan (Sepuar). Munich: Lincom Eur.

Jenner PN. 1974. The development of the registers in Standard Khmer. See Nguyen 1974, pp. $47-60$

Joseph B. 1983. The Synchrony and Diachrony of the Balkan Infinitive: A Study in Areal, General, and Historical Linguistics. Cambridge, UK: Cambridge Univ. Press

Keller R. 1994. On Language Change: The Invisible Hand in Language. London/New York: Routledge

Kendon A. 2004. Gesture: Visible Action as Utterance. Cambridge, UK: Cambridge Univ. Press Khanittanan W. 2001. Khmero-Thai: the great change in the history of the Thai language of the Chao Phraya Basin. In Proceedings of the 11th Meeting of the Southeast Asian Linguistics Society, ed. S Burusphat, pp. 375-92. Tempe, AZ: Centre for Southeast Asian Stud.

Kölver U. 1991. Local prepositions and serial verb constructions in Thai. In Partizipation: das Spracbliche Erfassen von Sacbverbalten, ed. H Seiler, W Premper, pp. 485-508. Tübingen: Narr

Koptjevskaja-Tamm M, Wälchli B. 2001. The Circum-Baltic languages. An areal-typological approach. In Circum-Baltic Languages. Typology and Contact, Vol. 2: Grammar and Typology, ed. Ö Dahl, M Koptjevskaja-Tamm, pp. 615-750. Amsterdam/Philadelphia: Benjamins

Kratochvil P. 1968. The Chinese Language Today. London: Hutchinson

Kruspe N. 2004. A Grammar of Semelai. Cambridge, UK: Cambridge Univ. Press

Laland K, Odling-Smee J. 2000. The evolution of the meme. In Darwinizing Culture: The Status of Memetics as a Science, ed. R Aunger, pp. 121-41. Oxford: Oxford Univ. Press

Leach E. 1964 (1954). Political Systems of Highland Burma. London: Athlone

Le Page RB, Tabouret-Keller A. 1985. Acts of Identity: Creole-Based Approaches to Language and Ethnicity. Cambridge, UK: Cambridge Univ. Press

Levinson SC. 1995. Interactional biases in human thinking. In Social Intelligence and Interaction: Expressions and Implications of the Social Bias in Human Intelligence, ed. Goody, pp. 221-60. Cambridge, UK: Cambridge Univ. Press

Levinson SC. 2000. Presumptive Meanings: The Theory of Generalized Conversational Implicature. Cambridge, MA/London: MIT Press

Li CN. 1986. The rise and fall of tones through diffusion. Berkeley Linguist. Soc. 12:173-85

Li CN, Thompson SA. 1976. Subject and topic: a new typology of language. In Subject and Topic, ed. CN Li, pp. 457-89. New York: Academic

Li FK. 1977. A Handbook of Comparative Tai. Honolulu: Univ. Hawaii Press

Long Y, Zheng G. 1998. The Dong Language in Guizhou Province, China. Arlington: Summer Inst. Linguist., Univ. Tex.
An important statement of the need to get the units of analysis right in understanding language change.

A classic anthropological account of structured social interaction between neighboring ethnic groups; an important description of the widespread pattern of relations between Tai and other ethnic groups in MSEA.

Questions the empirical reality of "languages" as whole and distinct systems, stressing the importance of ethnic identity as a key factor in linguistic processes. 
Explicates the possibility of the diffusion of semantic organization independent of surface form.

Demonstrates the value of computational modeling as a way of testing hypotheses in this domain.

A ground-breaking exploration of linguistic diversity as an essentially historical and geographical problem.
Luke KK. 1990. Utterance Particles in Cantonese Conversation. Amsterdam: Benjamins

Luo YX. 1997. The Subgroup Structure of the Tai Languages: A Historical-Comparative Study. Berkeley: Univ. Calif. Press

Masica C. 1976. Defining a Linguistic Area: South Asia. Chicago: Chicago Univ. Press

Maspero H. 1912. Phonétique historique de la langue annamite: les initiales. Bull. Ecole Fr. Extrême-Orient 12:1-27

Matisoff JA. 1973a. The Grammar of Labu. Berkeley: Univ. Calif. Press

Matisoff JA. 1973b. Tonogenesis in Southeast Asia. In Southern California Occasional Papers in Linguistics, No. 1, ed. LM Hyman, pp. 72-95. Los Angeles: Univ. South. Calif.

Matisoff JA. 1978. Variational Semantics in Tibeto-Burman: The 'Organic' Approach to Linguistic Comparison. Philadelphia: Inst. Study Hum. Issues

Matisoff JA. 1986. Hearts and minds in Southeast Asian languages and English: an essay in the comparative lexical semantics of psycho-collocations. Cah. Linguist. Asie Orient. 15:5-57

Matisoff JA. 1991a. Areal and universal dimensions of grammatization in Lahu. In Approaches to Grammaticalization, ed. EC Traugott, B Heine, pp. 383-453. Amsterdam: Benjamins

Matisoff JA. 1991b. Sino-Tibetan linguistics: present state and future prospects. Annu. Rev. Anthropol. 20:469-504

MatisoffJA. 2001. Genetic versus contact relationship: prosodic diffusability in Southeast Asian languages. See Aikhenvald \& Dixon 2001, pp. 291-327

Matthews S, Yip V. 1994. Cantonese: A Comprehensive Grammar. London/New York: Routledge McNeill D. 1992. Hand and Mind: What Gestures Reveal About Thought. Chicago: Chicago Univ. Press

Migliazza B. 1996. Mainland Southeast Asia: a unique linguistic area. Notes Linguist. 75:17-25

Milroy L. 1980. Language and Social Networks. Oxford: Basil Blackwell

Moerman M. 1988. Talking Culture: Ethnography and Conversation Analysis. Philadelphia: Univ. Penn. Press

Moseley C, Asher RE, eds. 1994. Atlas of the World's Languages. London: Routledge

Muysken P. 2000. From linguistic areas to areal linguistics: a research proposal. See Gilbers et al. 2000, pp. 263-75

Nettle D. 1997. On the status of methodological individualism. Curr. Anthropol. 38:283-86

Nettle D. 1999. Linguistic Diversity. Oxford: Oxford Univ. Press

Nguyen DH. 1980. Language in Vietnamese Society. Carbondale, IL: Asia Books

Nguyen DL, ed. 1974. Southeast Asian Linguistic Studies. Canberra: Pac. Linguist. Vol. 1

Nichols J. 1992. Linguistic Diversity in Space and Time. Chicago: Chicago Univ. Press

Norman J. 1988. Chinese. Cambridge, UK: Cambridge Univ. Press

Noss RB. 1964. Thai Reference Grammar. Washington, DC: Foreign Serv. Inst.

Oey EM. 1990. Psycho-collocations in Malay: a Southeast Asian areal feature. Linguist. TibetoBurman Area 13:141-58

Packard JL. 2000. The Morphology of Chinese. Cambridge, UK: Cambridge Univ. Press

Premsrirat S. 1987. Khmu, a Minority Language of Thailand. Canberra: Pac. Linguist.

Ramsey SR. 1987. The Languages of China. Princeton, NJ: Princeton Univ. Press

Ratanakul S, Thomas D, Premsrirat S, eds. 1985. Southeast Asian Linguistic Studies Presented to Andre-G. Haudricourt. Bangkok: Mahidol Univ.

Ratliff M. 1992. Meaningful Tone: A Study of Tonal Morphology in Compounds, Form Classes, and Expressive Phrases in White Hmong. DeKalb: North. Ill. Univ. Cent. Southeast Asian Stud.

Ratliff M. 2004. Vocabulary of environment and subsistence in the Hmong-Mien Protolanguage. In Hmong/Miao in Asia, ed. N Tapp, J Michaud, C Culas, G Yia Lee, pp. 147-65. Chiang Mai: Silkworm Books 
Reinhorn M. 1980. Grammaire de la langue lao. Paris: Inst. Natl. Lang. Civilis. Orient., Univ. Sorbonne Nouvelle

Rogers EM. 1995. Diffusion of Innovations. New York: Free Press

Ross M. 2001. Contact-induced change in Oceanic languages in North-West Melanesia. See Aikhenvald \& Dixon 2001, pp. 134-66

Ross M. 2003. Diagnosing prehistoric language contact. In Motives for Language Change, ed. R Hickey, pp. 174-98. Cambridge, UK: Cambridge Univ. Press

Sagart L. 2001. Vestiges of Archaic Chinese derivational affixes in modern Chinese dialects. See Chappell 2001b, pp. 123-42

Samerchai P. 1998. Tai migration in interdisciplinary perspective: physical anthropology. Presented at 1st Int. Conf. Tai Stud., Bangkok

Sapir E. 1907. Preliminary report on the language and mythology of the Upper Chinook. Am. Anthropol. 9:533-44

Sapir E. 1921. Language: An Introduction to the Study of Speech. Orlando/San Diego/New York/London: Harcourt Brace Jovanovich

Saul JE, Wilson NF. 1980. Nung Grammar. Arlington: Summer Inst. Linguist., Univ. Tex.

Schelling TC. 1971. Dynamic models of segregation. 7. Math. Sociol. 1:143-86

Schelling TC. 1978. Micromotives and Macrobebaviour. New York: Norton

Schober MF, Clark HH. 1989. Understanding by addressees and overhearers. Cogn. Psychol. 21:211-32

Sherzer J. 1973. Areal linguistics in North America. Curr. Trends Linguist. 10:749-95

Simpson A. 2001. Focus, presupposition and light predicate raising in East and Southeast Asian languages. 7. East Asian Linguist. 10:89-128

Simpson J. 2002. From common ground to syntactic construction: associated path in Warlpiri. See Enfield 2002b, pp. 287-308

Sperber D. 1985. Anthropology and psychology: towards an epidemiology of representations. Man 20:73-89

Steinberg DJ, ed. 1987. In Search of Southeast Asia. Honolulu: Univ. Hawaii Press. 2nd ed.

Stolz T. 2002. No Sprachbund beyond this line! On the age-old discussion of how to define a linguistic area. In Mediterranean Languages: Paper from the MEDTYP Workshop, Tirrenia, June 2000, ed. P Ramat, T Stolz, pp. 259-81. Bochum: Univ. Dr. N. Brockmeyer

Strecker D. 1987. The Hmong-Mien languages. Linguist. Tibeto-Burman Area 10:1-11

Stuart-Fox M. 1998. The Lao Kingdom of Lan Xang: Rise and Decline. Bangkok: White Lotus

Sybesma R. 2004. Zhuang as Tai with Chinese characteristics: postverbal 'can' in Zhuang, Cantonese, Vietnamese, and Lao. Typescript, NWO/IIAS/Leiden Cent. Linguist.

Thomas DM. 1969. Chrau affixes. Mon-Khmer Stud. 3:90-107

Thomason SG. 2000a. Linguistic areas and language history. See Gilbers et al. 2000, pp. $311-27$

Thomason SG. 2000b. On the unpredictability of contact effects. Estud. Sociol. 1:173-82

Thomason SG. 2001. Language Contact: An Introduction. Edinburgh: Edinburgh Univ. Press

Thomason SG, Kaufman T. 1988. Language Contact, Creolization, and Genetic Linguistics. Berkeley: Univ. Calif. Press

Thompson LC. 1987 (1965). A Vietnamese Grammar. Honolulu/Seattle: Univ. Hawaii Press/Univ. Wash. Press

Thurgood G. 1996. Language contact and the direction of internal drift: the development of tones and registers in Chamic. Language 72:1-31

Thurgood G. 1999. From Ancient Cham to Modern Dialects: Two Thousand Years of Language Contact and Change. Hawaii: Univ. Hawaii Press
A key insight into the ontology of cultural phenomena, proposing that culture (including language) is best described as a population of cognitive representations distributed across populations of individuals. 
Thurgood G, La Polla RJ, eds. 2003. The Sino-Tibetan Languages. London: Routledge Tosco M. 2000. Is there an 'Ethiopian Language Area'? Anthropol. Linguist. 42:329-65

Trubetzkoy N. 1930. Proposition 16. In Actes du Prem. Congr. Int. Linguist. à La Haye, 10-15 Avril 1928, pp. 17-18. Leiden: Sijthoff

Van der Auwera J. 1998. Revisiting the Balkan and Meso-American linguistic areas. Lang. Sci. 20:259-70

Voetz FKE, Kilian-Hatz C, eds. 2001. Ideophones. Amsterdam: Benjamins

Wang J, Zheng G. 1993. An Outline Grammar of Mulao. Canberra: Aust. Natl. Univ.

Weinreich U, Labov W, Herzog M. 1968. Empirical foundations for a theory of language change. In Proceedings of the Texas Conference on Historical Linguistics, ed. W Lehmann, pp. 97-195. Austin: Univ. Tex. Press

Wilkins DP. 1996. Natural tendencies of semantic change and the search for cognates. In The Comparative Method Reviewed, ed. M Durie, M Ross, pp. 264-304. New York: Oxford Univ. Press

Wyatt DK. 1984. Thailand: A Short History. Chiang Mai: Silkworm Books 
Frontispiece

Sally Falk Moore ............................................................... xvi

\section{Prefatory Chapter}

Comparisons: Possible and Impossible

Sally Falk Moore

\section{Archaeology}

Archaeology, Ecological History, and Conservation

Frances M. Hayashida

Archaeology of the Body

Rosemary A. Foyce

Looting and the World's Archaeological Heritage: The Inadequate

Response

Neil Brodie and Colin Renfrew

Through Wary Eyes: Indigenous Perspectives on Archaeology

foe Watkins

The Archaeology of Black Americans in Recent Times

Mark P. Leone, Cheryl Fanifer LaRoche, and Fennifer 7. Babiarz

\section{Biological Anthropology}

Early Modern Humans

Erik Trinkaus

Metabolic Adaptation in Indigenous Siberian Populations

William R. Leonard, F. Fosh Snodgrass, and Mark V. Sorensen

The Ecologies of Human Immune Function

Thomas W. McDade 


\section{Linguistics and Communicative Practices}

New Directions in Pidgin and Creole Studies

Marlyse Baptista

Pierre Bourdieu and the Practices of Language

William F. Hanks

Areal Linguistics and Mainland Southeast Asia

N.F. Enfield

Communicability, Racial Discourse, and Disease

Charles L. Briggs

Will Indigenous Languages Survive?

Michael Walsh

Linguistic, Cultural, and Biological Diversity

Luisa Maffi 599

\section{International Anthropology and Regional Studies}

Caste and Politics: Identity Over System

Dipankar Gupta

Indigenous Movements in Australia

Francesca Merlan

Indigenous Movements in Latin America, 1992-2004: Controversies,

Ironies, New Directions

Fean E. Fackson and Kay B. Warren

\section{Sociocultural Anthropology}

The Cultural Politics of Body Size

Helen Gremillion

Too Much for Too Few: Problems of Indigenous Land Rights in Latin

America

Anthony Stocks....

Intellectuals and Nationalism: Anthropological Engagements

Dominic Boyer and Claudio Lomnitz....

The Effect of Market Economies on the Well-Being of Indigenous

Peoples and on Their Use of Renewable Natural Resources

Ricardo Godoy, Victoria Reyes-García, Elizabeth Byron, William R. Leonard, and Vincent Vadez 
An Excess of Description: Ethnography, Race, and Visual Technologies

Deborah Poole....

Race and Ethnicity in Public Health Research: Models to Explain

Health Disparities

William W. Dressler, Kathryn S. Oths, and Clarence C. Gravlee

Recent Ethnographic Research on North American Indigenous

Peoples

Pauline Turner Strong

The Anthropology of the Beginnings and Ends of Life

Sharon R. Kaufman and Lynn M. Morgan

Immigrant Racialization and the New Savage Slot: Race, Migration, and Immigration in the New Europe

Paul A. Silverstein

Autochthony: Local or Global? New Modes in the Struggle over

Citizenship and Belonging in Africa and Europe

Bambi Ceuppens and Peter Geschiere...

Caste and Politics: Identity Over System

Dipankar Gupta

The Evolution of Human Physical Attractiveness

Steven W. Gangestad and Glenn 7. Scheyd

Mapping Indigenous Lands

Mac Chapin, Zachary Lamb, and Bill Threlkeld

Human Rights, Biomedical Science, and Infectious Diseases Among

South American Indigenous Groups

A. Magdalena Hurtado, Carol A. Lambourne, Paul Fames, Kim Hill,

Karen Cheman, and Keely Baca

Interrogating Racism: Toward an Antiracist Anthropology

Leith Mullings

Enhancement Technologies and the Body

Linda F. Hogle

Social and Cultural Policies Toward Indigenous Peoples: Perspectives

from Latin America

Guillermo de la Peña

Surfacing the Body Interior

fanelle S. Taylor 


\section{Theme 1: Race and Racism}

Race and Ethnicity in Public Health Research: Models to Explain Health Disparities

William W. Dressler, Kathryn S. Oths, and Clarence C. Gravlee

Communicability, Racial Discourse, and Disease

Charles L. Briggs

Immigrant Racialization and the New Savage Slot: Race, Migration, and Immigration in the New Europe

Paul A. Silverstein

The Archaeology of Black Americans in Recent Times

Mark P. Leone, Cheryl Fanifer LaRoche, and Fennifer F. Babiarz

Interrogating Racism: Toward an Antiracist Anthropology

Leith Mullings ....

\section{Theme 2: Indigenous Peoples}

The Effect of Market Economies on the Well-Being of Indigenous

Peoples and on Their Use of Renewable Natural Resources

Ricardo Godoy, Victoria Reyes-García, Elizabeth Byron, William R. Leonard, and Vincent Vadez

Recent Ethnographic Research on North American Indigenous

Peoples

Pauline Turner Strong

Will Indigenous Languages Survive?

Michael Walsh

Autochthony: Local or Global? New Modes in the Struggle over

Citizenship and Belonging in Africa and Europe

Bambi Ceuppens and Peter Geschiere.

Through Wary Eyes: Indigenous Perspectives on Archaeology

foe Watkins

Metabolic Adaptation in Indigenous Siberian Populations

William R. Leonard, 7. Fosh Snodgrass, and Mark V. Sorensen

Indigenous Movements in Australia

Francesca Merlan

Indigenous Movements in Latin America, 1992-2004: Controversies,

Ironies, New Directions

Fean E. Fackson and Kay B. Warren 
Linguistic, Cultural, and Biological Diversity

Luisa Maffi 599

Human Rights, Biomedical Science, and Infectious Diseases Among South American Indigenous Groups A. Magdalena Hurtado, Carol A. Lambourne, Paul Fames, Kim Hill, Karen Cheman, and Keely Baca

Social and Cultural Policies Toward Indigenous Peoples: Perspectives from Latin America Guillermo de la Peña

\section{Indexes}

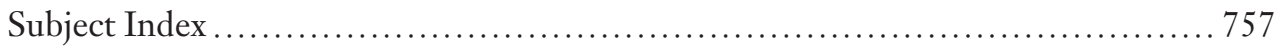

Cumulative Index of Contributing Authors, Volumes 26-34 ................... 771

Cumulative Index of Chapter Titles, Volumes 26-34 ........................... 774

\section{Errata}

An online log of corrections to Annual Review of Anthropology chapters may be found at http://anthro.annualreviews.org/errata.shtml 